\title{
Transthoracic Approach vs Transhiatal-Abdominal Approach in the Treatment of Locally Advanced Siewert Type II Esophagogastric Junctional Adenocarcinoma: A Retrospective Study
}

Huan Li ( $\nabla 1685049544 @ q q . c o m)$

Anhui Provincial Hospital Affiliated with Anhui Medical University https://orcid.org/0000-0002-5538-

2777

Xiaodong Zhu

Anhui Chest Hospital

Xinpeng Zhou

Wannan Medical College

Xinyu Mei

Anhui Provincial Hospital Affiliated with Anhui Medical University

\section{Research Article}

Keywords: Adenocarcinoma of the esophagogastric junction (AEG), Siewert type II, surgical approach, gastrectomy

Posted Date: October 25th, 2021

DOI: https://doi.org/10.21203/rs.3.rs-955175/v1

License: (1) (i) This work is licensed under a Creative Commons Attribution 4.0 International License.

Read Full License 


\section{Abstract}

Background The surgical approach for Siewert type II adenocarcinoma of the esophagogastric junction still remains controversial. This study aims to compare the differences between transthoracic approach and transhiatal-abdominal approach.

Methods Patients with Siewert type II adenocarcinoma of the esophagogastric junction underwent surgery from January 2010 to July 2015 were analyzed retrospectively. They were divided into transthoracic approach group and transhiatal-abdominal approach group. Postoperative complications, surgical characteristics and 5-year survival rates of the two groups were compared by Chi-square test and log-rank test respectively, and the extent of gastrectomy was analyzed in subgroups. Finally, Cox univariate and multivariate analyses were conducted to predict the independent prognostic factors for long-term survival.

Result A total of 255 patients with Siewert type II adenocarcinoma of the esophagogastric junction were analyzed, 143 with transthoracic approach group, 112 with transhiatal-abdominal approach group and the 5 -year survival rate was $37.8 \%$ and $40.2 \%$ respectively $(P=0.575)$. The incidence of positive proximal margins $(0.70 \%$ vs. $6.25 \%, P=0.023)$ and intraoperative bleeding volume $(175.15 \pm 110.44$ vs. $206.57 \pm$ $131.97 \mathrm{ml}, \mathrm{P}=0.046)$ in transthoracic approach group were lower. Transhiatal-abdominal approach group had fewer pulmonary infection $(8.04 \%$ vs. $17.48 \%, \mathrm{P}=0.028)$ and shorter hospitalization time (11.32 vs. 12.67 days, $P=0.008$ ). In subgroup analysis, the 5 -year survival rate of patients treated with partial gastrectomy was better than that of patients treated with total gastrectomy (44.8\% vs. $36.1 \%, P=0.038)$.

Conclusion Our study shows no significant difference between the two groups with regard to long-term survival. The transthoracic approach had more advantages for proximal margin and mediastinal lymph node dissection, while the transabdominal approach had less trauma to patients. Partial gastrectomy may be sufficient for patients with locally advanced disease. T stage and $\mathrm{N}$ stage were independent risk factors for long-term survival.

\section{Introduction}

Esophagogastric junction cancer refers to the carcinoma with an epicenter located within the range of 5 $\mathrm{cm}$ above and below the esophagogastric junction and crosses or contacts the dentate line(1).There were about 260,000 patients globally in 2012(2). Among them, east and Southeast Asia accounted for $59 \%$, more than half of the cases occurred in China, and adenocarcinoma of the esophagogastric junction (AEG) was the main pathologic type. Siewert et al(3) classified AEG into three types according to anatomic location. AEG I refers to the carcinoma with an epicenter located within 1 to $5 \mathrm{~cm}$ above the dentate line, AEG II to the carcinoma with an epicenter located within the range from $1 \mathrm{~cm}$ above to $2 \mathrm{~cm}$ below the dentate line and AEG III to the carcinoma with an epicenter located within 2 to $5 \mathrm{~cm}$ below the dentate line. 
AEG is mainly treated by surgery. Transthoracic esophagectomy plus adequate mediastinal lymph node dissection are adopted for AEG I, whereas total gastrectomy and transhiatal distal esophagectomy with lower mediastinal and abdominal (D2) node dissection are used for AEG III. As for AEG $\bigotimes$, which crosses the dentate line, is quite different from the other two types in terms of pathological source and lymphatic drainage direction(4-6). To date, the choice of transthoracic or transhiatal-abdominal as the surgical approach remains in debate(7-9). The aim of this retrospective observational single-center study is to analyze clinicopathological data for transthoracic and transhiatal-abdominal approaches at Anhui Provincial Hospital and compare postoperative complications, surgical characteristics and long-term survival rates between the two.

\section{Methods}

\section{Patients}

From January 2010 to July 2015, 942 patients with esophagogastric junction cancer underwent surgery at Anhui Provincial Hospital. The inclusion criteria were as follows: (I) locally advanced AEG II (T2, T3, T4); (II) no prior neoadjuvant chemo-/chemoradiotherapy before surgery; and (III) no distant metastasis. The exclusion criteria were (I) incomplete clinicopathological data or loss to follow-up, (II) palliative surgery or exploratory surgery, and (III) other malignant diseases. In total, 255 patients were enrolled, including 143 in the transthoracic approach group (TT group) and 112 in the transhiatal-abdominal approach group (TH group). Pathological staging was carried out according to the eighth edition of the TNM staging system(10). The present study is performed in accordance with the Declaration of Helsinki (as revised in 2013), Good Clinical Practice, and related laws.

\section{Surgical procedure}

The transthoracic approach was performed with proximal gastrectomy and distal esophagectomy from a lateral incision between the 7th and 8th ribs of the left-side chest, followed by esophagogastrostomy. The supradiaphragmatic lymph nodes, lower paraesophageal lymph nodes and subcarinal lymph nodes in the mediastinum and the perigastric lymph nodes in the abdomen were cleaned. In some patients, a left thoracoabdominal approach consisting of total gastrectomy and D2 lymphadenectomy, followed by esophagojejunostomy Roux-en-Y intrathoracic anastomosis was applied. The transhiatal-abdominal approach was performed with distal esophagectomy through the esophageal hiatus, followed by proximal or total gastrectomy and then esophagogastric anastomosis or Roux-en-Y esophagojejunostomy. D2 lymph node dissection was adopted for total gastrectomy and D1+ lymph node dissection for proximal gastrectomy.

\section{Follow-up observation}

Patients were followed up via phone calls or hospital visits to track their postoperative therapy status, survival status, survival time and quality of life after surgery. Overall survival (OS) was defined as the time from surgery to death or the last day of follow-up, which was October 01, 2020. 


\section{Statistical analysis}

All statistical analyses were performed using the software SPSS 19.0. Continuous variables are expressed as the mean \pm standard deviation $(x \pm s)$ and categorical variables as percentages. Continuous variables were compared by the t-test; categorical variables were compared using $X^{2}$ test or Fisher's exact test. Survival curves were derived from Kaplan-Meier estimates and compared by using the log-rank test. Prognostic factors were identified by univariate analysis. Factors with statistical significance $(P<0.05)$ were further analyzed by a Cox proportional-hazards model. We considered $\mathrm{P}<0.05$ as statistically significant. 
Table 1

Correlation of the clinicopathological characteristics between the TT and TH group

\begin{tabular}{|c|c|c|c|}
\hline Clinicopathological characteristics & $\operatorname{TT}(n=143)$ & $\mathrm{TH}(\mathrm{n}=112)$ & $\mathbf{P}$ \\
\hline Age(years,mean $\pm S D)$ & $64.78 \pm 7.70$ & $64.08 \pm 7.90$ & 0.480 \\
\hline Gender (Male/Female) & $118(82.52 \%) / 25(17.48 \%)$ & $88(78.57 \%) / 24(21.43 \%)$ & 0.427 \\
\hline Histological differentiation & & & 0.452 \\
\hline High & $3(2.10 \%)$ & $1(0.89 \%)$ & \\
\hline Mid & $63(44.06 \%)$ & $43(38.39 \%)$ & \\
\hline Poor & $77(53.85 \%)$ & $68(60.71 \%)$ & \\
\hline $\begin{array}{l}\text { Postoperative adjuvant } \\
\text { chemotherapy (yes/no) }\end{array}$ & $54(37.76 \%) / 89(62.24 \%)$ & $48(42.86 \%) / 64(57.14 \%)$ & 0.410 \\
\hline TNM stage & & & 0.269 \\
\hline 1 & $10(6.99 \%)$ & $5(4.46 \%)$ & \\
\hline 2 & $34(23.78 \%)$ & $30(26.79 \%)$ & \\
\hline 3 & $61(42.66 \%)$ & $57(50.89 \%)$ & \\
\hline 4 & $38(26.57 \%)$ & $20(17.86 \%)$ & \\
\hline T stage & & & 0.087 \\
\hline 2 & $24(16.78 \%)$ & $16(14.29 \%)$ & \\
\hline 3 & $97(67.83 \%)$ & $88(78.57 \%)$ & \\
\hline 4 & $22(15.38 \%)$ & $8(7.14 \%)$ & \\
\hline $\mathrm{N}$ stage & & & 0.239 \\
\hline 0 & $46(32.17 \%)$ & $36(32.14 \%)$ & \\
\hline 1 & $30(20.98 \%)$ & $32(28.57 \%)$ & \\
\hline 2 & $32(22.38 \%)$ & $27(24.11 \%)$ & \\
\hline 3 & 35 (24.48\%) & 17 (15.18\%) & \\
\hline
\end{tabular}

\section{Results}

The clinicopathological characteristics of the two groups are shown in Table 1. The baseline between groups was comparable. In subgroup analysis, the TNM stage was significantly later in those undergoing total gastrectomy than in those undergoing partial gastrectomy $(P<0.001$, Table 2$)$.

\section{Morbidity and mortality}


Postoperative complications and mortality are provided in Table 3. The incidence of pulmonary infection in the TT group was significantly higher than that in the TH group $(17.48 \%$ vs. $8.04 \%, P=0.028)$. In contrast, there was no significant difference in grade III- $\$ complications (based on the Clavien-Dindo grading system) or perioperative mortality between the two groups.

Table 2

Correlation of the clinicopathological characteristics between patients with total and partial gastrectomy

\begin{tabular}{|c|c|c|c|}
\hline Clinicopathological characteristics & $P G(n=142)$ & $T G(n=113)$ & $\mathbf{P}$ \\
\hline Age(years, mean $\pm S D)$ & $109(76.76 \%) / 33(23.24 \%)$ & $97(85.84 \%) / 16(14.16 \%)$ & 0.068 \\
\hline Histological differentiation & & & 0.189 \\
\hline High & $2(1.41 \%)$ & $2(1.77 \%)$ & \\
\hline Mid & $66(46.48 \%)$ & $40(35.40 \%)$ & \\
\hline Poor & $74(52.11 \%)$ & $71(62.83 \%)$ & \\
\hline $\begin{array}{l}\text { Postoperative adjuvant } \\
\text { chemotherapy (yes/no) }\end{array}$ & $58(40.85 \%) / 84(59.15 \%)$ & $44(38.94 \%) / 69(61.06 \%)$ & 0.757 \\
\hline TNM stage & & & $<0.001$ \\
\hline 1 & $12(8.45 \%)$ & $3(2.65 \%)$ & \\
\hline 2 & $40(28.17 \%)$ & $24(21.24 \%)$ & \\
\hline 3 & $66(46.48 \%)$ & $52(46.02 \%)$ & \\
\hline 4 & $24(16.90 \%)$ & $34(30.09 \%)$ & \\
\hline T stage & & & $<0.001$ \\
\hline 2 & $35(24.65 \%)$ & $5(4.42 \%)$ & \\
\hline 3 & $92(64.79 \%)$ & $93(82.30 \%)$ & \\
\hline 4 & 15 (10.56\%) & 15 (13.27\%) & \\
\hline
\end{tabular}


Table 3

Postoperative morbidity and mortality between two groups

\begin{tabular}{|llll|}
\hline Variable & TT(n=143) & TH(n=112) & P \\
\hline Total complications & $41(28.67 \%)$ & $26(23.21 \%)$ & 0.326 \\
\hline Clavien-Dindo Grade (Grade 2) & $32(22.38 \%)$ & $21(18.75 \%)$ & 0.479 \\
\hline Pulmonary infection & $25(17.48 \%)$ & $9(8.04 \%)$ & 0.028 \\
\hline arrhythmia & $2(1.40 \%)$ & $2(1.79 \%)$ & 1.000 \\
\hline Abdominal infection & 0 & $3(2.68 \%)$ & 0.083 \\
\hline Chylothorax & $1(0.70 \%)$ & 0 & 1.000 \\
\hline Gastrointestinal dysfunction & $1(0.70 \%)$ & $3(2.68 \%)$ & 0.323 \\
\hline Hypoproteinemia & $2(1.40 \%)$ & $2(1.79 \%)$ & 1.000 \\
\hline Wound infection & $1(0.70 \%)$ & $2(1.79 \%)$ & 0.584 \\
\hline Clavien-Dindo Grade (Grade 3-4) & $9(6.29 \%)$ & $5(4.46 \%)$ & 0.524 \\
\hline Abdominal haemorrhage & 0 & $2(1.79 \%)$ & 0.192 \\
\hline Respiratory failure & $2(1.40 \%)$ & $1(0.89 \%)$ & 1.000 \\
\hline Chylothorax & $5(3.50 \%)$ & $2(1.79 \%)$ & 0.471 \\
\hline Liver and kidney failure & $1(0.70 \%)$ & 0 & 1.000 \\
\hline Pulmonary embolism & $1(0.70 \%)$ & 0 & 1.000 \\
\hline 30-days mortality & $1(0.70 \%)$ & $2(1.79 \%)$ & 0.584 \\
\hline
\end{tabular}

\section{Surgical characteristics}

Surgery-related characteristics are listed in Table 4. Positive proximal margin $(0.7 \%$ vs. $6.25 \%, P<0.05)$ and bleeding volume $(175.15 \pm 110.44 \mathrm{vs.} 206.57 \pm 131.97 \mathrm{ml}, \mathrm{P}=0.046)$ rates in the TT group were lower than those in the TH group. However, postoperative hospitalization time was shorter in the TH group than in the TT group (11.32 \pm 3.68 vs. $12.67 \pm 4.04$ days, $P=0.008)$. Nevertheless, there was no significant difference in the total number of lymph nodes dissected and celiac lymph nodes dissected between the groups. Although the total number of lymph node dissections was slightly higher in the TT group than in the TH group (15.47 \pm 6.92 vs. $13.93 \pm 5.92, P=0.062)$, the opposite result was found for the number of lymph nodes dissected in the abdominal cavity (TH $13.49 \pm 5.82 \mathrm{vs}$. TT $12.16 \pm 5.89, \mathrm{P}=$ 0.073). The average number of thoracic lymph nodes in the TT group was 2.75 ; these lymph nodes were rarely cleaned in TH group. Finally, the celiac lymph node metastasis rate in the TT and TH groups was $62.9 \%$ and $68.8 \%$, respectively $(P=0.333)$, and the thoracic lymph node metastasis rate was $14.7 \%$ in the TT group. 
Table 4

Comparison of the different surgery-related characteristics between the TT and TT group

\begin{tabular}{|llll|}
\hline Variable & TT(n=143) & TH(n=112) & P \\
\hline Total number of removed lymph nodes & $15.47 \pm 6.92$ & $13.93 \pm 5.92$ & 0.062 \\
\hline $\begin{array}{l}\text { Number of removed lymph node in } \\
\text { abdomen }\end{array}$ & $12.16 \pm 5.89$ & $13.49 \pm 5.82$ & 0.073 \\
$\begin{array}{l}\text { Number of removed lymph node in } \\
\text { thorax }\end{array}$ & $2.75 \pm 3.43$ & $0.06 \pm 0.34$ & $<0.001$ \\
\hline MLR in abdomen & $90(62.9 \%)$ & $77(68.8 \%)$ & 0.333 \\
\hline MLR in thorax & $21(14.69 \%)$ & - & - \\
\hline Blood loss & $175.15 \pm 110.44$ & $206.57 \pm 131.97$ & 0.046 \\
\hline $\begin{array}{l}\text { Proximal margin status } \\
\text { Positive/Negative) }\end{array}$ & $1(0.70 \%) / 142(99.30 \%)$ & $7(6.25 \%) / 105(93.75 \%)$ & 0.023 \\
\hline Postoperative hospital stay (d) & $12.67 \pm 4.04$ & $11.32 \pm 3.68$ & 0.008 \\
\hline
\end{tabular}

MLR (Metastatic lymph node ratio) = number of patients with positive lymph nodes $/$ the number of patients collected in the station

\section{Survival and prognostic factors}

The 5-year OS rates in the TT group, TH group and the entire study cohort were $37.8 \%, 40.2 \%$ and $38.8 \%$, respectively. No significant difference in terms of OS between the two groups was found (Fig. 1-A). In subgroup analysis, the 5-year OS rates of patients undergoing transthoracic total gastrectomy and transhiatal-abdominal total gastrectomy were $26.1 \%$ and $34.7 \%$, respectively (Fig. 1-B). The 5-year OS of patients undergoing transthoracic partial gastrectomy and transhiatal-abdominal partial gastrectomy was $42.7 \%$ and $50 \%$, respectively $(P=0.349$, Fig. $1-C)$, that of patients undergoing transthoracic total and partial gastrectomy was $26.1 \%$ and $42.7 \%$, respectively ( $P=0.069$, Fig. $1-D)$, and that of patients undergoing transhiatal-abdominal total and partial gastrectomy was $34.7 \%$ and $50.0 \%$, respectively $(P=0.116$, Fig. 1-E), all with no significant difference. In subgroup analysis, the 5-year OS rate of patients treated with partial gastrectomy was significantly higher than that of patients treated with total gastrectomy (44.8\% vs. $36.1 \%, \mathrm{P}=0.038$, Fig. $1-\mathrm{F})$. Moreover, multivariate analysis of survival showed that $T$ and $N$ stage was an independent risk factor for prognosis $(P<0.05)$ but that age, sex, gastrectomy and surgical approach had no significant impact on the long-term survival of patients (Table 5).

\section{Discussion}

The mainstay treatment of AEG II is surgery $(11,12)$, but the choice of surgical approach, the scope of lymph node dissection and the optimal extent of gastrectomy are still debatable $(8,9,13)$. We conducted 
this study to analyze the different outcomes of surgical-related characteristics and survival rate between the transthoracic and transhiatal-abdominal approaches to explore optimal treatment for AEG II.

It has been reported that the incidence of postoperative complications of a transthoracic approach for AEG II is significantly higher than that of a transabdominal approach $(7,14,15)$. In our study, the incidence of complications was significantly higher in the TT group than in the TH group $(17.48 \% \mathrm{vs}$. $8.04 \%, P=0.028$ ), which may be explained by the fact that the transthoracic approach leads to more mechanical lung injury. In accordance with some previous work $(15,16)$, there was no significant difference in the incidence of other grade II complications or in anastomotic fistula and other serious complications (grade III- $\rrbracket$ ) between the two groups. Consequently, the 30-day postoperative mortality was not significantly different between the groups, indicating a similar safety with these two surgical approaches for AEG II.

Lymphatic drainage in AEG II occurs simultaneously to the thoracic cavity and abdominal cavity due to the location $(17,18)$. Previous studies have shown that a sufficient number and extent of lymph node dissection are independent risk factors affecting the long-term survival of patients $(19,20)$. Some studies have suggested that the transhiatal-abdominal approach can remove more lymph nodes $(7,21)$, though other studies have reported no difference between them(22). In this study, the total number of lymph nodes dissected in the TT group was slightly higher than that in the TH group, but with no significant difference, indicating that for total lymph node cleaning efficiency, the two surgical approach are essentially similar. In general, it is relatively difficult to dissect lymph nodes along the celiac artery, splenic artery and common hepatic artery with the transthoracic approach, especially the traditional left transthoracic approach, though middle and lower mediastinal lymph nodes are accessible. In this study, the thoracic lymph node metastasis rate in the TT group was $14.7 \%$, indicating that mediastinal lymph node dissection is necessary for AEG II surgery.

The incidence of positive proximal margins in the TH group was significantly higher than that in the TT group. This result was consistent with Parry $\mathrm{K}$ et al(23), suggesting that the transthoracic approach is related to a higher average resection length of the esophagus and $\mathrm{R} 0$ resection rate(24). Combined with previous reports $(24,25)$, the transthoracic approach appears to be suitable with esophageal invasion of 3 $\mathrm{cm}$ or more for AEG II. In the present study, the hospitalization time of patients undergoing the transhiatalabdominal approach was shorter than that of patients undergoing transthoracic surgery, consistent with previous reports $(7,8)$. These findings indicate that compared with the transthoracic approach, the transabdominal approach involves less trauma, less influence on respiratory function and faster recovery. Therefore, the transabdominal approach is more suitable for patients in a relatively poor general condition, especially those with poor pulmonary function.

\section{Table 5: Survival related multivariate analysis}




\begin{tabular}{|c|c|c|c|c|c|c|}
\hline \multirow[t]{2}{*}{ Variable } & \multicolumn{2}{|c|}{$\begin{array}{l}\text { 5-year survival related } \\
\text { factors }\end{array}$} & \multirow[t]{2}{*}{$\mathbf{P}$} & \multicolumn{2}{|c|}{ multivariate analysis } & \multirow[t]{2}{*}{$\mathbf{P}$} \\
\hline & HR & $\mathrm{Cl} 95 \%$ & & HR & $\mathrm{Cl} 95 \%$ & \\
\hline Gender (Male vs Female) & 1.255 & $(0.817-1.926)$ & 0.299 & - & - & - \\
\hline Age (>=65 VS <65) & 1.238 & $(0.901-1.702)$ & 0.187 & - & - & - \\
\hline \multicolumn{7}{|l|}{ T stage } \\
\hline 2(reference) & 1 & - & - & 1 & - & - \\
\hline 3 & 3.396 & $(1.779-6.480)$ & $<0.001$ & 1.997 & $\begin{array}{l}(1.010- \\
3.948)\end{array}$ & 0.047 \\
\hline 4 & 6.919 & (3.314-14.447) & $<0.001$ & 3.234 & $\begin{array}{l}(1.468- \\
7.122)\end{array}$ & 0.004 \\
\hline \multicolumn{7}{|l|}{$\mathrm{N}$ stage } \\
\hline 0 (reference) & 1 & - & - & 1 & - & - \\
\hline 1 & 2.897 & $(1.768-4.747)$ & $<0.001$ & 2.506 & $\begin{array}{l}(1.513- \\
4.150)\end{array}$ & $<0.001$ \\
\hline 2 & 2.918 & $(1.759-4.840)$ & $<0.001$ & 2.436 & $\begin{array}{l}(1.450- \\
4.094)\end{array}$ & 0.001 \\
\hline 3 & 6.927 & $(4.218-11.375)$ & $<0.001$ & 5.136 & $\begin{array}{l}(3.042- \\
8.671)\end{array}$ & $<0.001$ \\
\hline \multicolumn{7}{|l|}{$\begin{array}{l}\text { Histological } \\
\text { differentiation }\end{array}$} \\
\hline High(reference) & 1 & - & - & 1 & - & - \\
\hline Mid & 2.545 & $(0.352-18.394)$ & 0.335 & - & - & - \\
\hline Poor & 4.106 & $(0.572-29.454)$ & 0.160 & - & - & \\
\hline $\begin{array}{l}\text { Gastrectomy } \\
\text { (total/partial) }\end{array}$ & 1.393 & $(1.014-1.913)$ & 0.041 & 1.091 & $\begin{array}{l}(0.789- \\
1.509)\end{array}$ & 0.597 \\
\hline $\begin{array}{l}\text { Surgery approach } \\
\text { (TT/TH) }\end{array}$ & 1.095 & $(0.795-1.507)$ & 0.579 & - & - & - \\
\hline $\begin{array}{l}\mathrm{P}<0.05 \text { in univariate ana } \\
\text { included in multivariate a }\end{array}$ & $\begin{array}{l}\text { is or pr } \\
\text { ysis }\end{array}$ & ous research pro & the varia & e relate & to prognosis & \\
\hline
\end{tabular}

Overall, the influence of a surgical approach on the long-term survival of patients is an important factor to evaluate its rational use, and results in previous studies are controversial. For example, Susan et al(26) searched an institutional prospectively maintained database and found the survival time of the transabdominal approach to be shorter than that of the right thoracoabdominal approach for AEG II, but this result may be related to the higher proportion of elderly patients over 70 years old in the transhiatalabdominal approach group. The JCOG9502(16) study showed that the median survival time and five-year 
survival rate of patients undergoing the transhiatal-abdominal approach were slightly higher than those of patients undergoing the left thoracoabdominal approach, but with no significant difference. In addition, Parry $\mathrm{K}$ et al(23) reported no difference in five-year survival rate between the transhiatalabdominal and transthoracic approach, similar to our results. Indeed, subgroup analysis of gastrectomy revealed no significant difference in five-year survival between the subgroups. Therefore, we hold the opinion that the long-term effects of transthoracic and transabdominal approaches are similar for the surgical treatment of AEG II.

The optimal extent of gastrectomy for Siewert type II AEG, including total and partial gastrectomy, is always selected according to tumor size, stage, location and surgeon's preference. Zhao et al(27) analyzed the effects of transhiatal-abdominal total and partial gastrectomy on patients and concluded that the latter may have a better five-year survival rate in AEG II patients at IA-IIIA stage and a tumor diameter less than $3 \mathrm{~cm}$; for patients at later stages, the extent of gastrectomy had no significant impact on long-term prognosis. Similarly, we conclude that for locally advanced AEG II, patients who underwent partial gastrectomy had a higher five-year survival rate than those who underwent total gastrectomy ( $44.8 \%$ vs. $36.1 \%, P=0.038)$. In subgroup analysis, we also found that patients treated with partial gastrectomy had a higher survival advantage than those treated with total gastrectomy. We believed this was related to the choice of surgical method, as the tumor stage of the patients treated with total gastrectomy was later. Survival-related multivariate analysis in this study showed $\mathrm{T}$ stage and $\mathrm{N}$ stage to be independent risk factors affecting the prognosis of AEG II patients, and we consider tumor stage as the main factor related to the survival of these patients.

This study is a single-center retrospective study. Although relatively strict screening conditions were set, there may be a certain degree of selection bias, and the qualified sample size was relatively small. A prospective study needs to be designed to obtain more objective results.

\section{Conclusion}

In conclusion, our study shows no significant difference between the transthoracic and transhiatalabdominal approaches for AEG II patients with regard to the 5-year survival rate. Both approaches are comparably safe for AEG II. However, the transthoracic approach with partial gastrectomy is a better choice if proximal margins cannot be safely achieved (usually esophageal tumor extension of more than $3 \mathrm{~cm}$ ), whereas the transhiatal-abdominal approach appears to be preferable for patients with a relatively poor general condition, especially those with poor pulmonary function, due to less trauma. Partial gastrectomy is sufficient compared with total gastrectomy for locally advanced AEG II. Finally, T stage and $\mathrm{N}$ stage are independent risk factors for survival in AEG II.

\section{Abbreviations}

adenocarcinoma of the esophagogastric junction

AEG

Page $11 / 15$ 
Transhiatal-abdominal approach

$\mathrm{TH}$

transthoracic approach

TT

total gastrectomy

TG

partial gastrectomy

PG

transhiatal-abdominal partial gastrectomy

THPG

transhiatal-abdominal total gastrectomy

THTG

transthoracic partial gastrectomy

TTPG

transthoracic total gastrectomy

TTTG

Overall survival

OS

Metastatic lymph node ratio

MLR

\section{Declarations}

Acknowledgements: The authors are grateful to their friend Fei Zhang, Xiaoxue Wang and Wangyu Wu for the assistance provided, the same as all of the patients included.

\section{Author Contributions:}

Huan Li₫Xiaodong Zhu凹Xinpeng Zhou: data collectionliterature search

Huan Li: statistical analysis $\square$ manuscript preparation

Xinyu Mei: study design, provision of materials and resources, date interpretation.

Funding $\mathbb{N}$ Not applicable.

Availability of data and materials: The datasets used and/or analysed during the current study are available from the corresponding author on reasonable request.

Ethical statement and consent to participate: This study was a retrospective study with a waiver of ethical approval and informed consent.

Consent for publication: Not applicable. 
Competing interests: The authors declare that they have no competing interests in this section.

\section{References}

1. Kumamoto T, Kurahashi Y, Niwa H, Nakanishi Y, Okumura K, Ozawa R, et al. True esophagogastric junction adenocarcinoma: background of its definition and current surgical trends. Surg Today. 2020;50(8):809-14.

2. Colquhoun A, Arnold M, Ferlay J, Goodman KJ, Forman D, Soerjomataram I. Global patterns of cardia and non-cardia gastric cancer incidence in 2012. Gut. 2015;64(12):1881-8.

3. Siewert JRSH. Classification of adenocarcinoma of the oesophagogastric junction. Br J Surg. 1998;85:1457-9.

4. Carneiro F, Moutinho C, Pera G, Caldas C, Fenger C, Offerhaus J, et al. Pathology findings and validation of gastric and esophageal cancer cases in a European cohort (EPIC/EUR-GAST). Scand J Gastroenterol. 2007;42(5):618-27.

5. Maeda H, Okabayashi T, Nishimori I, Sugimoto T, Namikawa T, Dabanaka K, et al. Clinicopathologic features of adenocarcinoma at the gastric cardia: is it different from distal cancer of the stomach? J Am Coll Surg. 2008;206(2):306-10.

6. Liu K, Zhang W, Chen X, Chen X, Yang K, Zhang B, et al. Comparison on Clinicopathological Features and Prognosis Between Esophagogastric Junctional Adenocarcinoma (Siewert II/III Types) and Distal Gastric Adenocarcinoma: Retrospective Cohort Study, a Single Institution, High Volume Experience in China. Med (Baltim). 2015;94(34):e1386.

7. Yang ZF, Wu DQ, Wang JJ, Feng XY, Zheng JB, Hu WX, et al. Surgical approach for Siewert type II adenocarcinoma of the esophagogastric junction: transthoracic or transabdominal? -a single-center retrospective study. Ann Transl Med. 2018;6(23):450.

8. Zhang W, Chen X, Liu K, Yang K, Chen X, Zhao Y, et al. Comparison of survival outcomes between transthoracic and transabdominal surgical approaches in patients with Siewert-II/III esophagogastric junction adenocarcinoma: a single-institution retrospective cohort study. Chin J Cancer Res. 2016;28(4):413-22.

9. Omloo JM, Lagarde SM, Hulscher JB, Reitsma JB, Fockens P, van Dekken H, et al. Extended transthoracic resection compared with limited transhiatal resection for adenocarcinoma of the mid/distal esophagus: five-year survival of a randomized clinical trial. Ann Surg. 2007;246(6):9921000. discussion -1 .

10. Rice TW, Ishwaran H, Ferguson MK, Blackstone EH, Goldstraw P. Cancer of the Esophagus and Esophagogastric Junction: An Eighth Edition Staging Primer. J Thorac Oncol. 2017;12(1):36-42.

11. Han WH, Eom BW, Yoon HM, Reim D, Kim YW, Kim MS, et al. The optimal extent of lymph node dissection in gastroesophageal junctional cancer: retrospective case control study. BMC Cancer. 2019;19(1):719. 
12. Ajani JA, D'Amico TA, Bentrem DJ, Chao J, Corvera C, Das P, et al. Esophageal and Esophagogastric Junction Cancers, Version 2.2019, NCCN Clinical Practice Guidelines in Oncology. J Natl Compr Canc Netw. 2019;17(7):855-83.

13. Kaixuan Zhu YX, Jiaxin Fu. Proximal Gastrectomy versus Total Gastrectomy for Siewert Type II Adenocarcinoma of the Esophagogastric Junction: A Comprehensive Analysis of Data from the SEER Registry. Dis Markers. 2019;10(1):1155.

14. Xing J, Liu M, Xu K, Gao P, Tan F, Yao Z, et al. Short-Term and Long-Term Outcomes Following Transhiatal versus Right Thoracoabdominal Resection of Siewert Type II Adenocarcinoma of the Esophagogastric Junction. Cancer Manag Res. 2020;12:11813-21.

15. Reddavid R, Strignano P, Sofia S, Evangelista A, Deiro G, Cannata G, et al. Transhiatal distal esophagectomy for Siewert type II cardia cancer can be a treatment option in selected patients. Eur $\mathrm{J}$ Surg Oncol. 2019;45(10):1943-9.

16. Sasako M, Sano T, Yamamoto S, Sairenji M, Arai K, Kinoshita T, et al. Left thoracoabdominal approach versus abdominal-transhiatal approach for gastric cancer of the cardia or subcardia: a randomised controlled trial. The Lancet Oncology. 2006;7(8):644-51.

17. YUICHI HOSOKAWA TK, MASARU KONISHI. Recurrence Patterns of Esophagogastric Junction Adenocarcinoma According to Siewert's Classification After Radical Resection. ANTICANCER RESEARCH; 2014.

18. Chen XD, He FQ, Chen M, Zhao FZ. Incidence of lymph node metastasis at each station in Siewert types / adenocarcinoma of the esophagogastric junction: A systematic review and meta-analysis. Surg Oncol. 2020;35:62-70.

19. Peng J, Wang WP, Yuan Y, Hu Y, Wang Y, Chen LQ. Optimal Extent of Lymph Node Dissection for Siewert Type II Esophagogastric Junction Adenocarcinoma. Ann Thorac Surg. 2015;100(1):263-9.

20. Wu XN, Liu CQ, Tian JY, Guo MF, Xu MQ. Prognostic significance of the number of lymph nodes examined in node-negative Siewert type II esophagogastric junction adenocarcinoma. Int J Surg. 2017;41:6-11.

21. Hosoda K, Yamashita K, Katada N, Moriya H, Mieno H, Sakuramoto S, et al. Impact of lower mediastinal lymphadenectomy for the treatment of esophagogastric junction carcinoma. Anticancer Res. 2015;35(1):445-56.

22. Heger P, Blank S, Goossen K, Nienhuser H, Diener MK, Ulrich A, et al. Thoracoabdominal versus transhiatal surgical approaches for adenocarcinoma of the esophagogastric junction-a systematic review and meta-analysis. Langenbecks Arch Surg. 2019;404(1):103-13.

23. Parry K, Haverkamp L, Bruijnen RC, Siersema PD, Ruurda JP, van Hillegersberg R. Surgical treatment of adenocarcinomas of the gastro-esophageal junction. Ann Surg Oncol. 2015;22(2):597-603.

24. Tosolini C, Reim D, Schirren R, Feith M, Friess H, Novotny AR. Influence of the surgical technique on survival in the treatment of carcinomas of the true cardia (Siewert Type II) - Right thoracoabdominal vs. transhiatal-abdominal approach. Eur J Surg Oncol. 2019;45(3):416-24. 
25. Feng F, Tian Y, Xu G, Liu S, Liu Z, Zheng G, et al. The length of proximal margin does not influence the prognosis of Siewert type II/III adenocarcinoma of esophagogastric junction after transhiatal curative gastrectomy. Springerplus. 2016;5:588.

26. Blank S, Schmidt T, Heger P, Strowitzki MJ, Sisic L, Heger U, et al. Surgical strategies in true adenocarcinoma of the esophagogastric junction (AEG II): thoracoabdominal or abdominal approach? Gastric Cancer. 2018;21(2):303-14.

27. Zhao B, Zhang Z, Mo D, Lu Y, Hu Y, Yu J, et al. Optimal Extent of Transhiatal Gastrectomy and Lymphadenectomy for the Stomach-Predominant Adenocarcinoma of Esophagogastric Junction: Retrospective Single-Institution Study in China. Front Oncol. 2018;8:639.

\section{Figures}
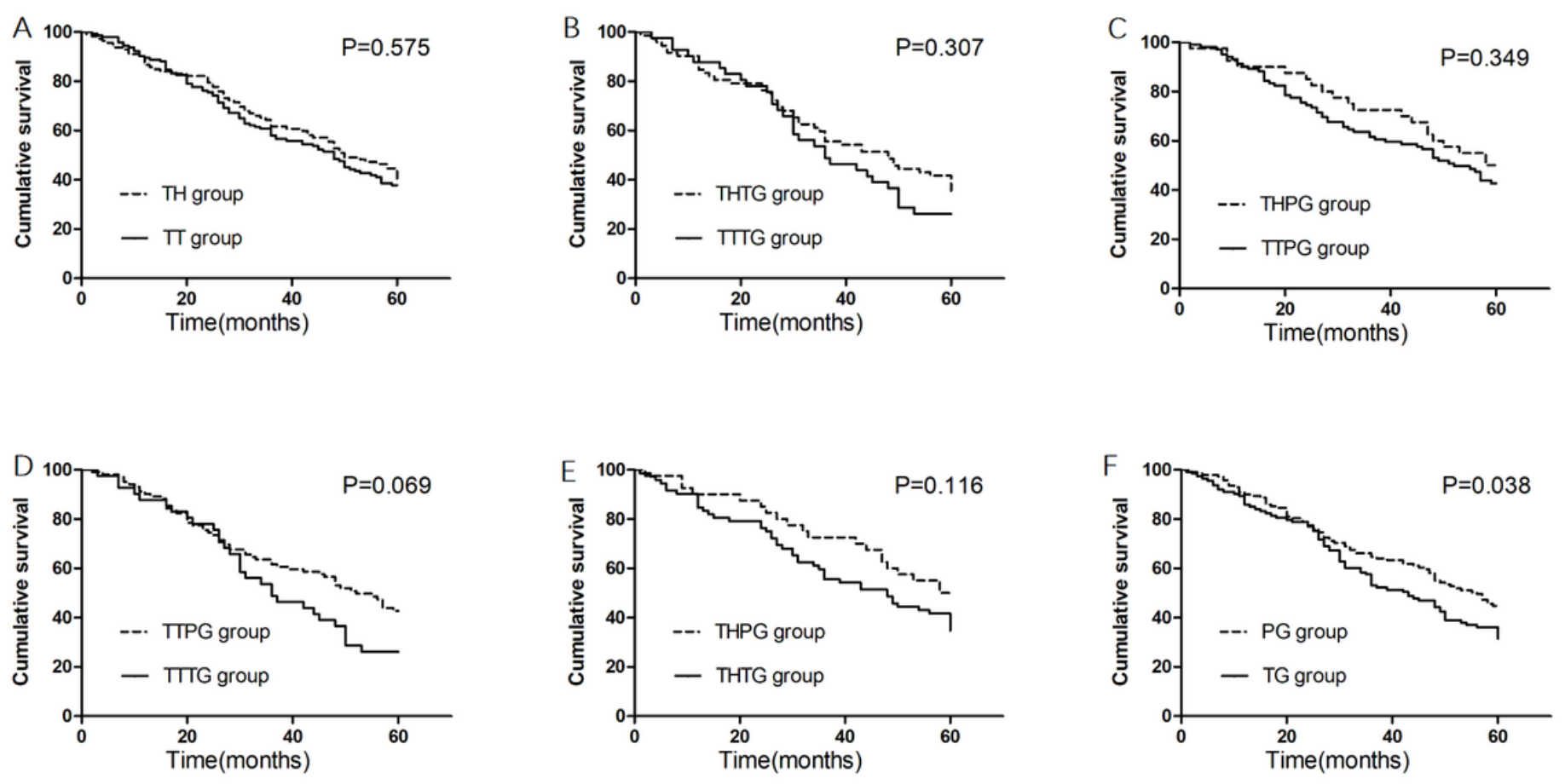

\section{Figure 1}

Fig 1-A, 5-year OS rate(TT 37.8\% vs TH 40.2\%, P=0.575);Fig 1-B, 5-year OS rate(TTTG $26.1 \%$ vs THTG $34.7 \%, P=0.307$ ); Fig 1-C, 5-year OS rate (TTPG 42.7\% vs THPG 50\%, P=0.349); Fig 1-D, 5-year OS rate (TTTG $26.1 \%$ vs TTPG 42.7\%, $\mathrm{P}=0.069$ ); Fig 1-E, 5-year OS rate (THTG $34.7 \%$ vs THPG $50.0 \%, \mathrm{P}=0.116$ ); Fig 1-F, 5-year OS rate (PG 44.8\% vs TG 36.1\%, P=0.038); 